HARRAN ÜNIVERSITESI

MÜHENDISLIK DERGisi

HARRAN UNIVERSITY JOURNAL OF ENGINEERING

e-ISSN: 2528-8733

\section{HARRAN ÜNIVERSİTESI MÜHENDİSLİK DERGİSİ}

HARRAN UNIVERSITY JOURNAL of ENGINEERING

e-ISSN: 2528-8733 (ONLINE)

URL: http://dergipark.gov.tr/humder

\title{
Aerojel Yalıtım Keçelerinin Isıl ve Higrotermal Karakterizasyonu
}

\section{Thermal and Hygrothermal Characterization of Aerogel Insulation Blankets}

Yazar(lar) (Author(s)): Selena ALAN ${ }^{1, *}$, Gülden GÖKÇEN AKKURT ${ }^{2}$, Sedat AKKURT ${ }^{3}$, Hasan Çı̆̆ SEZER ${ }^{4}$ , Alper Çam ${ }^{5}$

${ }^{1}$ ORCID ID: 0000-0002-9639-8126

${ }^{2}$ ORCID ID: 0000-0002-3444-9610

${ }^{3}$ ORCID ID: 0000-0002-2534-5756

${ }^{4}$ ORCID ID: 0000-0002-1192-4319

${ }^{5}$ ORCID ID: 0000-0003-2980-7898

Bu makaleye şu şekilde atıfta bulunabilirsiniz (To cite to this article): Alan S., Gökçen Akkurt G., Akkurt S., Sezer H.Ç., Çam A., "Aerojel Yalıtım Keçelerinin Isıl ve Higrotermal Karakterizasyonu", Harran Üniversitesi Mühendislik Dergisi, 6(Özel sayı): 58-69, (2021).

Erişim linki (To link to this article): http://dergipark.gov.tr/humder/archive 


Mühendislik Dergisi

\title{
Aerojel Yalıtım Keçelerinin Isıl ve Higrotermal Karakterizasyonu
}

\author{
Selena ALAN ${ }^{1}$, *, Gülden GÖKÇEN AKKURT² , Sedat AKKURT² , Hasan Çı̆̆ SEZER ${ }^{4}$, Alper Çam ${ }^{5}$ \\ ${ }^{1}$ İzmir Yüksek Teknoloji Enstitüsü, Lisansüstü Eğitim Enstitüsü, Enerji Mühendisliği Yüksek Lisans Programı, 35433, Urla/İzmir/Türkiye \\ ${ }^{2}$ İzmir Yüksek Teknoloji Enstitüsü, Mühendislik Fakültesi, Enerji Sistemleri Mühendisliği Bölümü, 35433, Urla/İzmir/Türkiye \\ ${ }^{3}$ İzmir Yüksek Teknoloji Enstitüsü, Mühendislik Fakültesi, Malzeme Bilimi ve Mühendisliği Bölümü, 35433, Urla/İzmir/Türkiye \\ ${ }^{4-5}$ İzmir Jeotermal Enerji San. ve Tic. A.Ş., 35330, Balçova/İzmir/Türkiye
}

\begin{abstract}
$\ddot{O} \mathbf{z}$
Makale Bilgisi

Başvuru: 29/01/2021

Yayln: 01/11/2021

\section{Anahtar Kelimeler}

Aerojel

Yalitım

İzmir Jeotermal Enerji San. ve Tic. A.Ş., İzmir'in Narlıdere ve Balçova bölgesine jeotermal kaynaklarla bölgesel isıtma sağlayan bir kuruluştur. Bu çalışma, İzmir Jeotermal Enerji San. ve Tic. A.Ş. bünyesinde bulunan 1sı merkezlerinde vana, boru ve 1sı değiştirgeçleri ile şehir içinde dolaşmakta olan yaklaşık $450 \mathrm{~km}$ uzunluğundaki boruların yalıtımlarının yenilenmesi çalışmalarına temel oluşturmak amacıyla gerçekleştirilmiştir. Aerojel yalıtım malzemeleri, fiberlere tutunmuş aerojellerden oluşurlar ve oldukça gözenekli bir yapıya sahiptirler. Bu nedenle, 1S1 iletimleri kısıtlıdır ve bu özellik sayesinde yalıtım uygulamalarında kullanılmaktadır. Bu çalışmada üç farklı aerojel yalıtım keçesi İzmir Jeotermal Enerji San. ve Tic. A.Ş. bünyesinde oluşturulan bir düzeneğe uygulanmış, düzenekten basınç, yüzey ve ortam sıcaklığı ölçümleri alınmıştır. Aerojel yalıtım malzemelerinden alınan numuneler IYYTE-Tümleşik Araştırma Merkezi (TAM) bünyesinde çeşitli ölçüm ve analizlere tabi tutularak karakterize edilmiş ve isıl performans ile ıslatılamama özelliği açısından karşılaştırılmıştır.
\end{abstract}

Enerji Verimliliği

\section{Keywords}

Aerogel

Insulation

Energy Efficiency

\section{Thermal and Hygrothermal Characterization of Aerogel Insulation Blankets}

\begin{abstract}
İzmir Geothermal Inc. is a geothermal district-heating company that serves Narlıdere and Balçova regions of İzmir via $450 \mathrm{~km}$ of piping system that circulates the hot water throughout the district with the help of valves, pipes and heat exchangers. As the distance travelled by the hot water is excessively long, heat losses are common. Izmir Geothermal Inc. is interested in applying/renewing thermal insulation blankets wrapped around the pipes to minimize the heat losses. Porous aerogel insulation blankets that consist of micron-sized aerogel particles attached to glass fibers have been proposed as potentially effective insulation materials. Owing to their porous structure, glass fibers and the presence of aerogel particles, they are known to be efficient thermal insulators. In this study, three different aerogel insulation blankets are comparatively studied to assess their structures and thermal performances. A test setup was assembled by Izmir Geothermal Inc. on site and pressure, surface and ambient temperature measurements were taken. Samples taken from the aerogel insulation materials were characterized by various methods within the İzmir Institute of Technology - Integrated Research Center (IYTE-IRC) and compared based on thermal performance and non-wetting properties.
\end{abstract}

\section{GİRIŞ (INTRODUCTION)}

İlk aerojel, 1930'larda Samuel Stephens Kistler tarafından üretildi. Kistler, tungsten oksit, demir oksit, kalay oksit, selüloz, selüloz nitrat, jelatin, agar ve kauçuk gibi birçok malzemeden aerojeller hazırladı [1]. Aerojel keçelerin 1sı yalıtımında kullanılma fikri, dünyada ilk olarak 1997 yılında ortaya atılmıştır. 2004 yılından itibaren ise ticari ve endüstiyel alanlarda kullanılmaya başlanmıştır [2]. Isı yalıtım malzemeleri temel olarak binalarda duvar ve tavanlarda, sanayi ve endüstride soğutma odalarında, ekipman ve boru hatlarında kullanılırlar [3]. Cam yünü, taş yünü, cam köpüğü, XPS ekstrüde polistiren, EPS genleştirilmiş

\footnotetext{
*İletişim yazarı, e-mail: selenaalan@iyte.edu.tr

Bu çalışma, 05-06 Kasım 2020 tarihlerinde gerçekleştirilen GAPYENEV Uluslararası Yenilenebilir Enerji ve Enerji Verimliliği Kongresi’nde sözlü bildiri olarak sunulmuştur.
} 
polistiren yaygın kullanılan 1s1 yalıtım malzemelerindendir [4-5]. Isı yalıtımı hayatımızın birçok alanında büyük önem kazanmaktadır; yapılarda ve endüstride uygulanan 1s1 yalıtımı, aynı zamanda enerji verimliliğini arttırmakta yani maaliyetleri de ciddi ölçekte etkilemektedir [6]. Isı yalıtımı malzemelerinin yalıtım özelliklerinin arttırılması, malzemelerin uygulanabilirliğinin kolaylaştırılması ve enerji tasarrufunu arttırabilmesi adına çalışmalar yapılmaktadır.

Günümüzde aerojeller; bina, endüstriyel alanlar, uzay ve havacılıkta 1sı yalıtımı, akustik yalıtım, katalizör, kimyasal sensör, yakıt hücreleri, spor ekipmanları ve tekstil gibi alanlarda kullanılmaktadır [7-8]. Aerojeller; granül, monolit, levha ve keçe gibi farklı formlarda bulunabilirler. Aerojel granülleri ve monolitler sol-jel yöntemiyle sentezlenirken, aerojel keçe ve levhalar fiber, partikül ve opaklaştırıcıların takviyesi ile üretilir. Granül ve monolit aerojelin kırılgan yapısı nedeniyle, uygulama alanı sınırlıdır. Kırılganlığı azaltıp, mekanik bütünlüğü iyileştirmek için, aerojeller genellikle destekleyici fiber yapılarla güçlendirilir ve bu nedenle esnek 1sı yalıtım keçeleri olarak kullanılabilir [9].

Silika aerojeller, çok gözenekli, yüksek yüzey alanına sahip, düşük yoğunluklu ve ısı iletim katsayıları düşük olan ve bu özelliklerinden dolayı yalıtım uygulamalarında kullanılabilen malzemelerdir [10]. Fiber yapılara yedirilmiş keçe formunda kullanılırlar. Islatılamama özelliği aerojeller için önemli bir diğer özelliktir. Silika aerojel keçeler aerojellerin ıslatılamama özelliğinden dolayı hidrofobiktirler. Islatılamama özellikleri sayesinde küflenmeye karşı koruma sağlarlar [11]. Su ve nem tutmamaları sayesinde bina yalıtımı, boru yalıtımında kullanılabilmektedirler.

Jeotermal kaynaklı bölgesel 1sıtma sistemlerinde sıcak akışkanın 1sı kaybına engel olmak amacıyla genellikle 1sı yalıtım malzemesi olarak taş yünü vb. fiber keçeler kullanılmaktadır. Borularda su kaçakları olduğunda 1slanan bu malzemeler yalıtım özelliğinin azalmasına neden olmaktadır. Aerojel yalıtım malzemelerinin yalıtım özelliklerinin yanısıra sslatılamama özellikleri nedeniyle jeotermal uygulamalarda kullanılabileceği değerlendirilmektedir.

Bu çalışma, İzmir Jeotermal Enerji San. ve Tic. A.Ş. bünyesinde, İzmir'de Balçova-Narlıdere Jeotermal Bölgesel Isıtma Sistemi 1s1 merkezlerinde bulunan vana, boru ve 1s1 değiştirgeçleri ile şehir içinde dolaşmakta olan yaklaşık $450 \mathrm{~km}$ uzunluğundaki boruların yalıtımlarının yenilenmesi çalışmalarına temel oluşturmak amacıyla gerçekleştirilmiştir. Farklı üreticiler tarafından üretilen üç farklı aerojel yalıtım keçesiyle yürütülen bu çalışma, literatürde kullanılan klasik yalıtım malzemelerinin yerine aerojel içeren yalıtım keçelerinin jeotermal sistemlerde kullanılabilirliğini araştırmayı amaçlamaktadır. Yazarların bilgisi dahilinde bu çalışma, aerojel yalıtım keçelerinin jeotermal uygulamalarda kullanılabilirliği hakkındaki ilk çalışmadır.

\section{MATERYAL VE METOD (MATERIALS AND METHODS)}

Üç farklı ticari aerojel yalıtım keçesinin farklarının nereden kaynaklandığını karşılaştırmak ve en iyi ısıl ve 1slatılamama performansının belirlenmesi için planlanan çalışma;

A. test düzeneğinin oluşturulması ve düzenek üzerinde sıcaklık ölçümlerinin yapılması,

B. aerojel numunelerinin toplanmasi ve numune hazırlama,

C. IYYTE'de laboratuvar çalışmalarının yapılması ve

D. ölçüm ve analizlerin yorumlanması aşamalarından oluşmaktadır.

\section{A. Test düzeneğinin oluşturulması}

İzmir Jeotermal Enerji San. ve Tic. A.Ş. tarafından B4A kuyusunda test düzeneği hazırlanmış, düzenek ve ölçüm noktaları Şekil 1'de verilmiştir. Aynı sıcaklık ve basınçta jeotermal akışkan girişi olan, paralel bağlı 3 adet pislik tutucu çıkışındaki paslanmaz çelik vanalar üzerine 3 farklı aerojel numune uygulanmış, 4-5 gün işletme koşullarına maruz bırakılıp kararlı duruma geçmesi beklenmiştir. Düzenek üzerinde 2 noktadan basınç, 11 noktadan yüzey sıcaklığı, ortam sıcaklığı ve hava hızı ölçümleri alınmıştır. Bu çalışmada kullanılan aerojel keçelerin ikisi yabancı (A ve B) menşeli, biri yerli (C) üründür. 


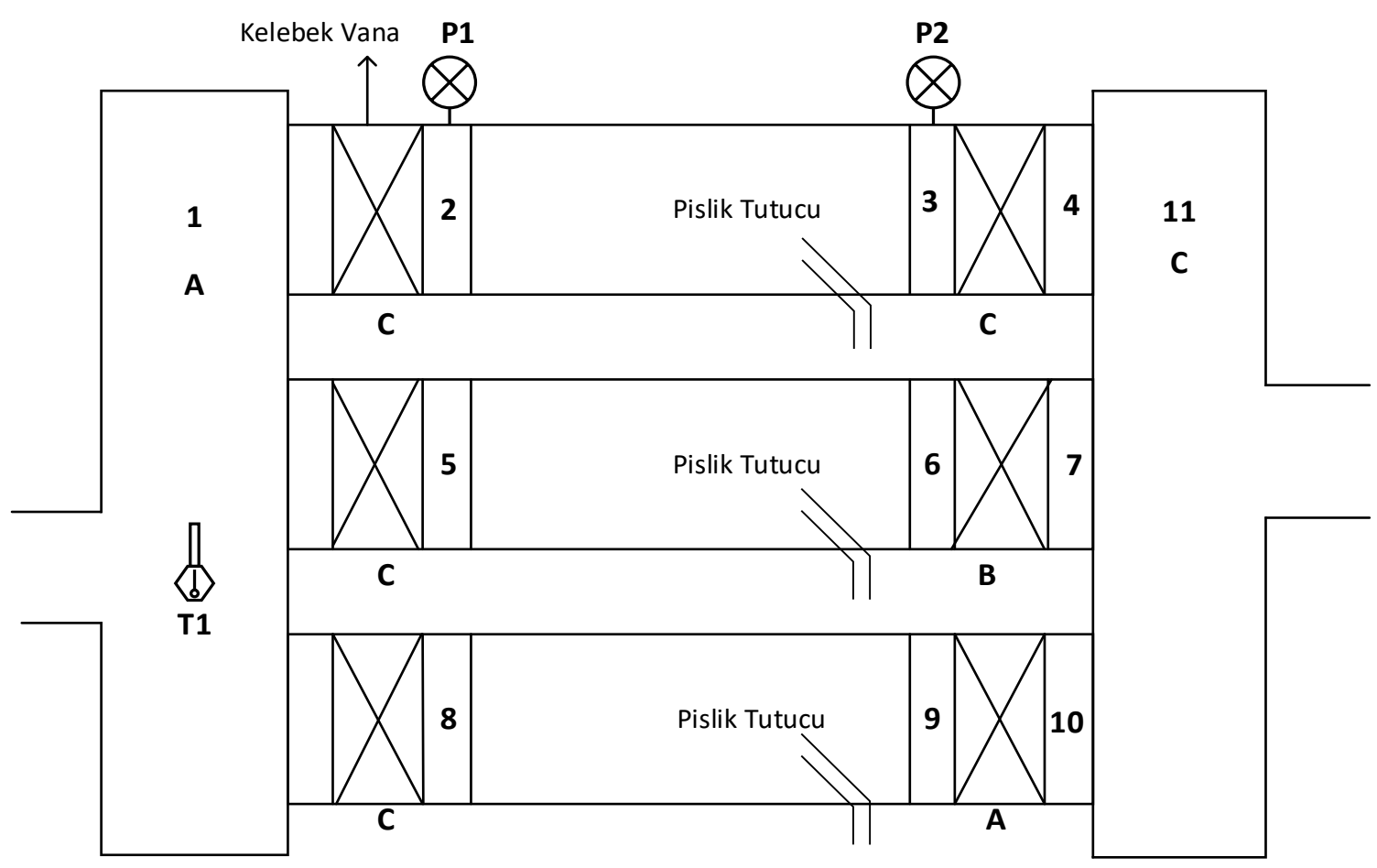

Şekil 1. Ölçüm düzeneği şematik gösterimi.

\section{B. Aerojel numunelerin toplanması}

Test düzeneğinde kullanılan aerojel keçeler monte edildikleri yerlerden sökülerek laboratuvar testleri için IYTE'ye getirilmiştir. Herbir analiz türüne uygun ebatlarda kesilerek kılıfından ayrılmış, numuneler hazırlanmıştır.

\section{Laboratuvar çalışmaları}

Numune hazırlıkları tamamlanan aerojel keçelerin analiz ve karakterizasyonu için IYTE-Tümleşik Araştırma Merkezi (TAM) bünyesinde;

- Yoğunluk ölçümleri,

- TGA (Thermogravimetric Analysis - Termogravimetrik Analiz),

- Optik mikroskop görüntüleri,

- SEM (Scanning Electron Microscope - Taramalı Elektron Mikroskobu),

- Temas açısı ölçümleri,

- EDX (Energy-dispersive X-ray spectroscopy - Enerji yayınımlı X ışınımı),

- Isı iletim katsayısı ölçümleri,

- XRD (X-Ray Diffraction - X-1şını difraktometresi),

- FTIR (Fourier-transform infrared spectroscopy - Fourier dönüşümlü kızılötesi spektrometresi) gözlemleri,

- Isı kapasitesi (özgül 1sı) ölçümleri gerçekleştirilmiştir.

\section{C.1. Yoğunluk ölçümleri}

Yoğunluk ölçümleri için 10x10x10 mm ebatlarında keçe numuneler kesilmiş ve 3 farklı sıcaklık için sabit hacimde kütle değişimleri belirlenmiş ve Denklem (1)'e göre yoğunluk hesaplanmıştır.

$$
\rho=\mathrm{m} / \mathrm{V}\left(\mathrm{kg} / \mathrm{m}^{3}\right)
$$


İlk hesaplamada numuneler ortam sıcaklı̆ğında $\left(30^{\circ} \mathrm{C}\right)$ tartılmış, ikinci hesaplamada ise etüvde $110^{\circ} \mathrm{C}$ 'ye 1sıttılarak 24 saat kurutulmuş ve tartılmıştır. Üçüncü hesaplama ise termogravimetrik analizlerde (TGA), $765^{\circ} \mathrm{C}^{\prime}$ ye kadar yapılan 1 sitma işlemi sonrasında yapılmıştır.

\section{C.2. Termogravimetrik analiz (TGA)}

Numuneler, analiz için hassas teraziye asılıyken anlık ağırlık ölçümleri alınarak $25^{\circ} \mathrm{C}$ 'den $765^{\circ} \mathrm{C}$ 'ye kadar $10^{\circ} \mathrm{C} / \mathrm{dk}$ 1sıtma hızında 1sıtılmıştır. Bu analizde amaç ısıtmaya bağlı bozunma tepkimelerini belirlemektir. Isıtma işlemi dakikada $50 \mathrm{ml}$ azotla gerçekleştirilmiştir.

\section{C.3. Optik mikroskop görüntüleri}

Her üç aerojel keçe numunesi, Nikon marka stereo zoom optik mikroskopta görüntülenmiştir.

\section{C.4. Taramalı elektron mikroskobu (SEM) gözlemleri}

Her üç aerojel keçe numunesi, Quanta Feg 250 marka ve model SEM'de inceleme öncesinde sputter coater (püskürtmeli kaplayıcı) cihazında ince bir altın tabakasıyla kaplanmıştır. Daha sonra, secondary electron (SE) modunda gözlemlenen numunelerin değişik büyütmelerdeki görüntüleri elde edilmiştir. Aerojel fiber çapları ve aerojel tutunumları gözlemlenmiştir.

\section{C.5. Temas açısı ölçümleri}

Aerojel numunelerin 1slatılamama (non-wetting) özelliklerini belirlemek için temas açısı ölçümleri yapılmıştır. Her üç numune ve numune kılıfı, Attension marka ve Theta model temas açısı ölçüm cihazında yaklaşık $3 \mu \mathrm{L}$ saf su kullanılarak ölçüme tabi tutulmuştur. Bir malzemenin 1slatılamama özelliği göstermesi için temas açısının $90^{\circ}$ 'den büyük olması beklenmektedir [12]. Temas açısı ne kadar büyükse 1slatılamama özelliği de o kadar iyidir.

\section{C.6. Enerji yayınımlı X ışınımı (EDX) gözlemleri}

Numunenin SEM cihazında yüksek hızda elektron demeti ile taranması sırasında oluşan x-1şınları incelenen bölgenin elementel kimyasal kompozisyonu hakkında fikir verir. EDX dedektörü, numunenin kimyasal kompozisyonunu belirlemede kullanılır. (EDX Oxford Inc.-Aztec). Analizler her numune için teker teker aerojel partikülü ve fiber (elyaf) için yapılmıştır.

\section{C.7. Isı iletim katsayısı analizleri}

Isı iletim katsayısı ölçümleri için KEM-QTM 500 marka ve model cihaz kullanılmıştır. Isı iletim katsayısı, $\lambda(\mathrm{W} / \mathrm{mK})$ ile gösterilmektedir.

\section{C.8. X-ışını difraktometresi (XRD) gözlemleri}

XRD, kristal/amorf yapıda olduğu düşünülen bir maddenin faz tanımlaması için kullanılır. Her üç aerojel keçe numunesi için analizler yapıllmıştır.

\section{C.9. Fourier dönüşümlü kızılötesi spektrometresi (FTIR) gözlemleri}

FTIR, organik veya inorganik bileşiklerin karakterize edilmesinde kullanılır. Analiz gözlemleri, malzemeyi oluşturan atomlar arasındaki bağların titreşimiyle oluşan frekanslara karşıllk gelen absorpsiyon pikleri ile sağlanır. Her malzemenin kendine has pik noktaları vardır.

\section{C.10. Isı kapasitesi (özgül ısı) ölçümleri}

Is1 kapasitesi $\left(C_{p}\right)$ ölçümleri, Diferansiyel Taramalı Kalorimetre (DSC) ile ölçülmüştür. Ölçümler her numune için $-10^{\circ} \mathrm{C}$ den başlayıp dakikada $10^{\circ} \mathrm{C}$ artırılarak $300^{\circ} \mathrm{C}$ 'de tamamlanmıştır. İşletme sıcaklığına 
bağlı olarak $C_{p}$ değerleri hesaplanabilir. Yoğunluk hesaplamasında kullanılan sıcaklıklardan olan ve ortalama jeotermal çalışma sıcaklığını temsil eden $110^{\circ} \mathrm{C}$ için $1 \mathrm{~s} 1$ kapasitesi değerleri hesaplanmıştır. Isıl iletkenlik ile 1sı kapasitesi ters orantılıdır.

\section{BULGULAR VE TARTIŞMA (RESULTS AND DISCUSSION)}

Aerojel yalıtım malzemesi seçimi için en önemli parametreler ısı iletim katsayısı ile temas açısı olsa da bu parametreleri etkileyebilecek olan, malzemelerin mikro-yapısının belirlenmesi ve yorumlanmasının önemli olduğu düşünülerek mikro-yapı ile ilgili Bölüm 2'de listelenen pek çok analiz yapılmış ve bu analizler yorumlanmıştır. İzmir Jeotermal A.Ş. bünyesindeki test düzeneği ölçüm verileri Şekil 1'deki numaralandırmaya göre Tablo1'de listelenmiştir.

Tablo 1. Test düzeneği ölçüm verileri.

\begin{tabular}{|l|l|l|}
\hline Ölçüm noktası & Sıcaklık $\left({ }^{\circ} \mathbf{C}\right)$ & Aerojel keçe tipi \\
\hline $\mathrm{T} 1$ & 102,0 & $\begin{array}{l}\text { Jeotermal akışkan } \\
\text { s1caklığ } 1\end{array}$ \\
\hline 1 & 42,8 & $\mathrm{~A}$ \\
\hline 2 & 42,8 & $\mathrm{C}$ \\
\hline 3 & 47,7 & $\mathrm{C}$ \\
\hline 4 & 44,2 & $\mathrm{C}$ \\
\hline 5 & 54,5 & $\mathrm{C}$ \\
\hline 6 & 53,3 & $\mathrm{~B}$ \\
\hline 7 & 48,3 & $\mathrm{~B}$ \\
\hline 8 & 48,0 & $\mathrm{C}$ \\
\hline 9 & 50,3 & $\mathrm{~A}$ \\
\hline 10 & 47,6 & $\mathrm{~A}$ \\
\hline 11 & 44,7 & $\mathrm{C}$ \\
\hline $\mathrm{T}_{0}$ & 36,2 & Ortam sicaklığ1 \\
\hline Ölçüm noktası & Basınç (bar) & Aerojel keçe tipi \\
\hline P1 & 2,1 & $\mathrm{C}$ \\
\hline P2 & 2,2 & $\mathrm{C}$ \\
\hline
\end{tabular}

\subsection{Yoğunluk ölçümleri}

Yapılan ölçümler sonucunda sıcaklığa bağlı olarak aerojel keçelerde bulunan bazı bileşenlerin uçtuğu ve kütle kaybı yaşandığı gözlemlenmiş̧ir. Firma katalog verilerinin ölçülen değerlerden çok yüksek olduğu görülmektedir. Yoğunluğu en yüksek keçe $\mathrm{C}$ keçesidir. $\mathrm{C}$ keçesini sırayla $\mathrm{B}$ ve $\mathrm{A}$ keçeleri takip etmektedir. $\mathrm{B}$ keçesi diğer keçelere göre $5 \mathrm{~mm}$ daha kalındır. Bu durum maliyet ve kullanım açısından dezavantaj olabilir.

\subsection{Termogravimetrik analiz (TGA)}

TGA analizleri sonucunda aerojel keçelerin $765^{\circ} \mathrm{C}$ 'de yakılmasıyla oluşan kütle kaybı A keçesi için yaklaşık \%5, B keçesi için yaklaşık \%6, C keçesi için ise yaklaşık \%4'dür. TGA analiz grafikleri Şekil 2'de gösterilmiştir. 

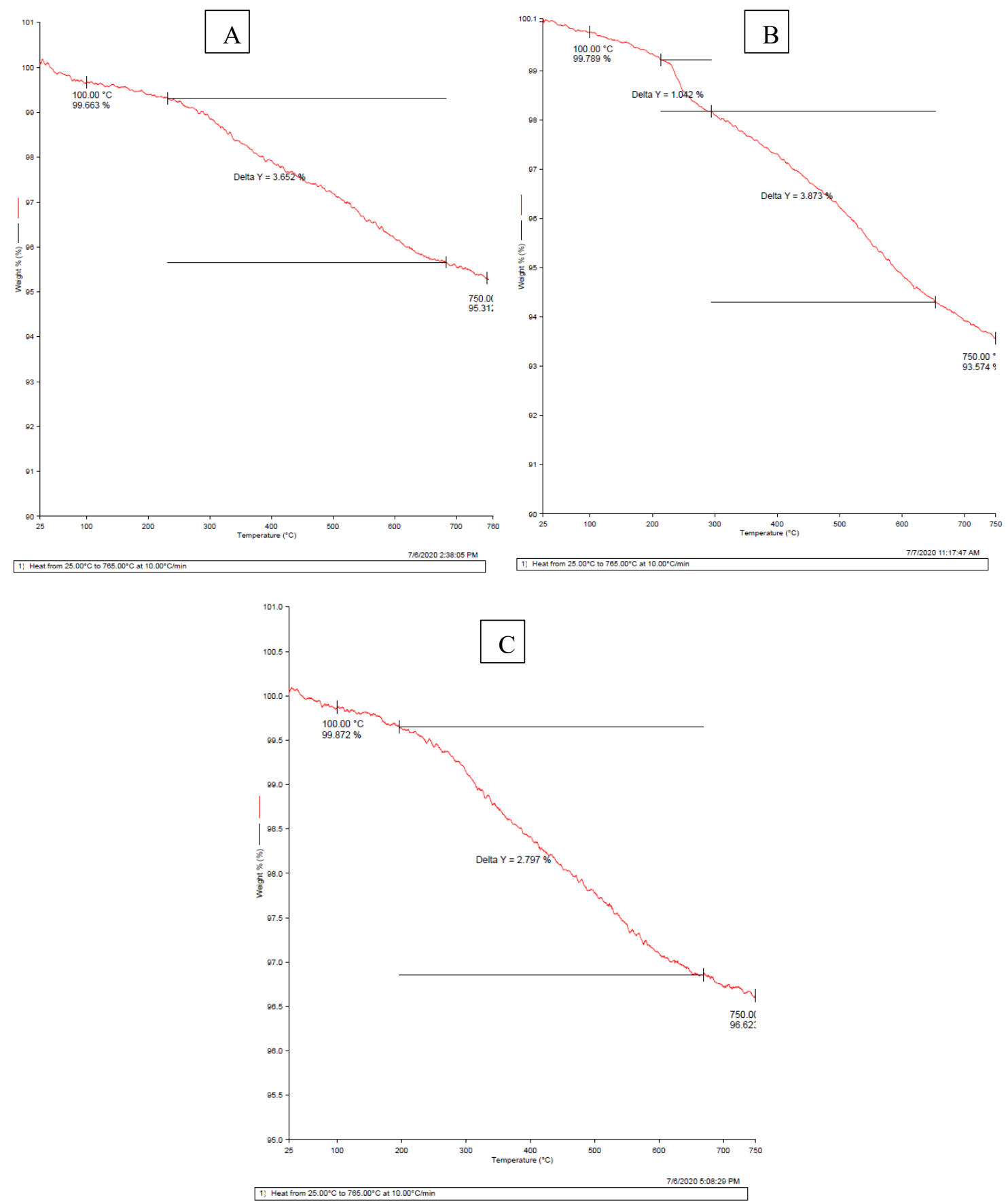

Şekil 2. Aerojel keçelerinin TGA grafikleri.

\subsection{Optik mikroskop görüntüleri}

Optik mikroskopla yaklaşık 40x büyütmede gözlemlenen numune görüntülerinde her üç numunenin de fiber elyafımsı şekle sahip olduğu gözlenmiştir. Numunelerin Stereo zoom optik mikroskop görüntüleri Şekil 3'te gösterilmiştir. 

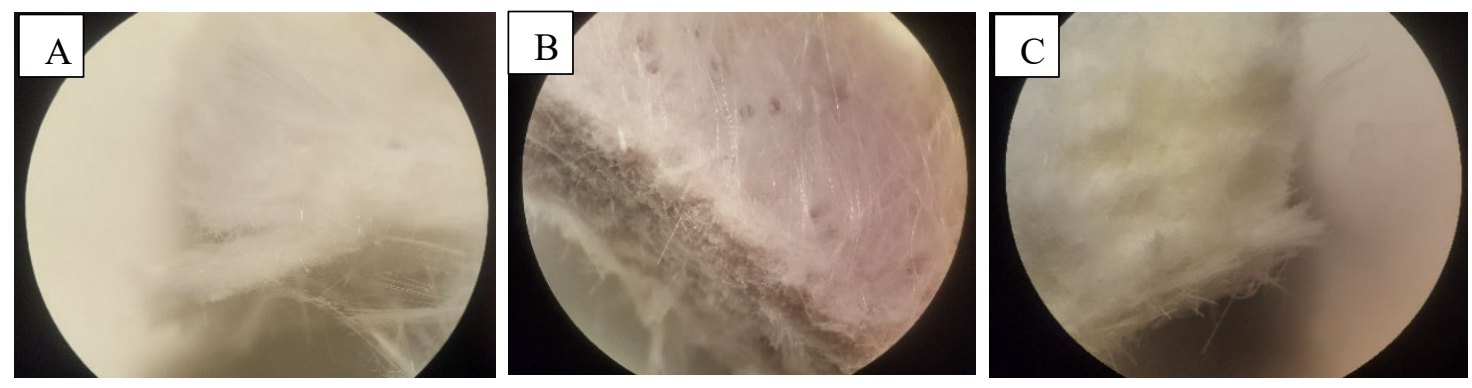

Şekil 3. Aerojellerin Stereo Zoom Optik mikroskop görüntüleri.

\subsection{Taramalı elektron mikroskobu (SEM) gözlemleri}

SEM görüntüleri sonucunda, her üç numunede de aerojellerin eş eksenli partikül formunda olduğu ve bazı silikat fiberlerine (cam elyaf) tutunduğu gözlenmiştir. Aerojel partiküllerinin düşük boyutları sebebiyle kolay havalandığ 1 (airborne) düşünüldüğünde, her bir yalıtım keçesi imalatı sırasında fiber yapı üzerine emdirilmek suretiyle imal edildikleri düşünülmektedir.

Ancak, numune hazırlama işlemi sırasında aerojel partiküllerinin üzerine tutundukları cam elyafların üzerinden dökülebileceği göz önünde bulundurulmalıdır. SEM görüntülerinden yola çıkılarak aerojel partiküllerinin fiberlere en güçlü tutunum sağladığ keçenin $C$ numunesine, en zayıf tutunumun ise A numunesine ait olduğu gözlemlenmiştir. $\mathrm{C}$ numunesinde, aerojel partiküllerinin boyutlarının diğer iki aerojel keçeye göre daha büyük boyutta olduğu da gözlemlenmiştir. Bu da 1sı yalıtım performansının sürekliliği açısından faydalı bir özelliktir. C numunesindeki tutunumun yüksek olmasından dolayı, B keçesine göre daha düşük yüzey sıcaklığı ölçülmesi muhtemeldir. Ayrıca bu özelliğinden dolayı C keçesinin zamana bağlı olarak performans kaybının da daha düşük olacağı düşünülmektedir. Şekil 4'te sırayla her üç aerojel keçenin 250x büyütmedeki SEM görüntüleri, Şekil 5'te ise 50000x büyütmedeki SEM görüntüleri yer almaktadır.
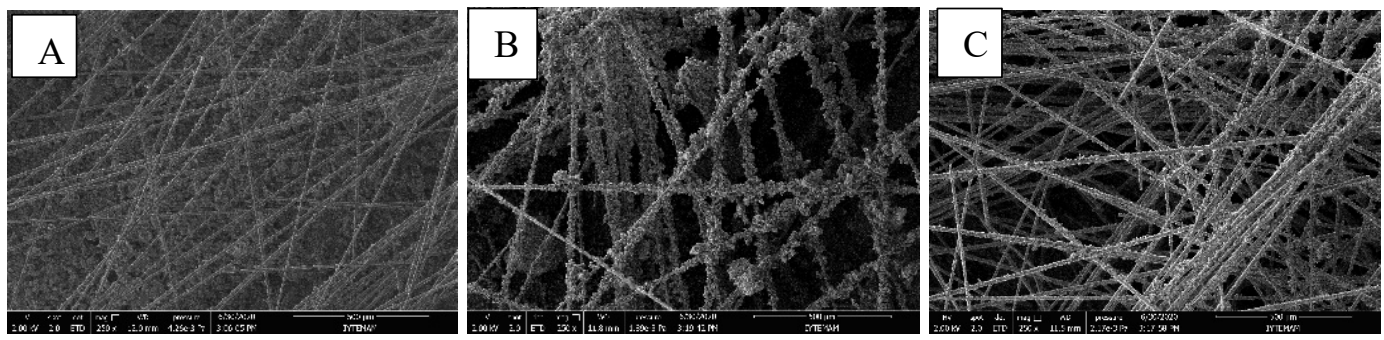

Şekil 4. Aerojel keçelerin 250x büyütmedeki SEM görüntüleri.
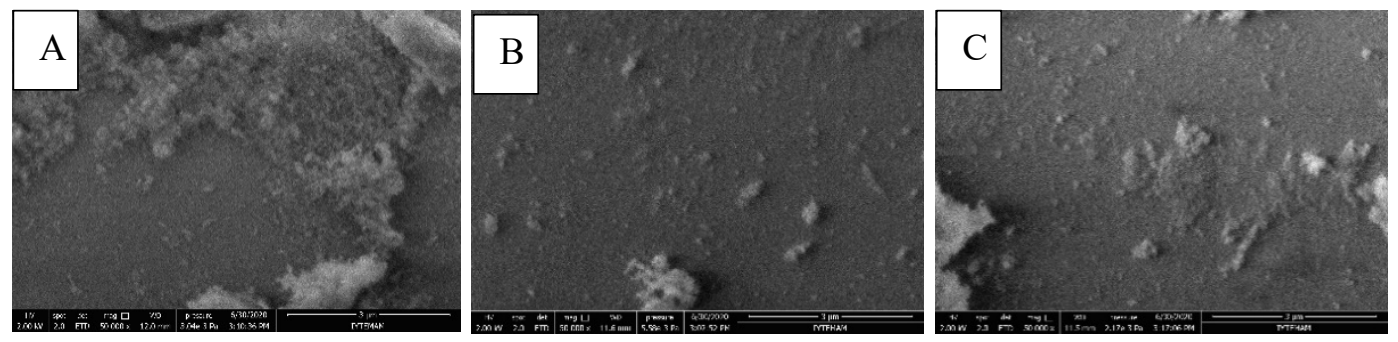

Şekil 5. Aerojel keçelerin 50000x büyütmedeki SEM görüntüleri.

\subsection{Temas açısı ölçümleri}

Aerojel üretici firmalar, üç ürünün de sslatılamama özelliği sergilediğini beyan etmiştir. Temas açısı ölçümleri sonucunda, A aerojel keçesinin diğer keçelere göre en iyi 1slatılamama özelliğine sahip olduğu, A'yı C ve B'nin izlediği görülmektedir. Şekil 6'da sırayla her üç aerojel keçenin temas açısı ölçüm görüntüleri sıralanmıştır. Kılıf olarak tüm aerojel keçeler için aynı kumaşın kullanıldığ 1 belirtilmiş olsa da renk farklılıkları görüldüğü için ayrı ayrı ölçüm yapılmıştır. Kılıf malzemesi, aerojel keçeyi dış ortamdan koruduğu için temas açısı ölçümü keçeye göre daha önemli görülmüştür. Kılıf ölçümlerine bakıldığında 
ise, temas açısı yüksekten düşüğe B, C ve A şeklindedir. Şekil 7'de sırayla her üç aerojel keçenin kılıflı temas açısı ölçüm görüntüleri sıralanmıştır.
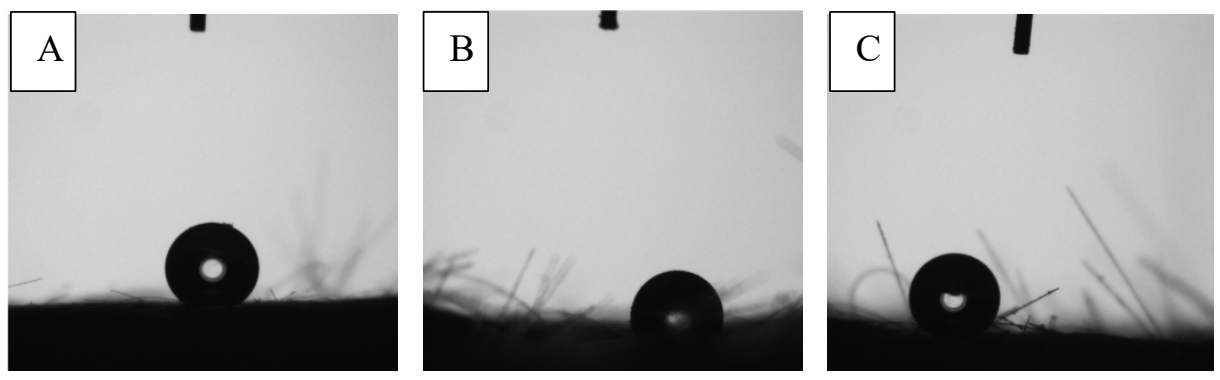

Şekil 6. Aerojel keçelerin temas açısı görüntüleri.
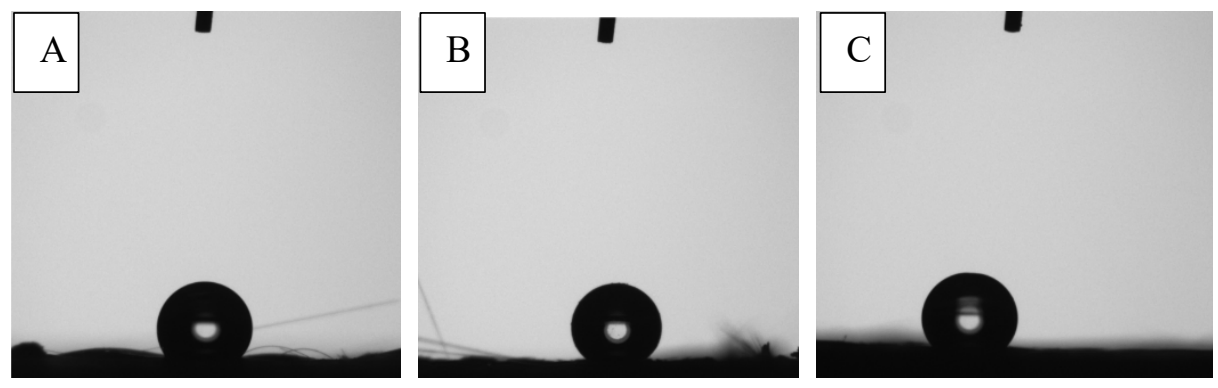

Şekil 7. Aerojel keçelerin kılıflı temas açısı görüntüleri.

\subsection{Enerji yayınımlı X ışınımı (EDX) gözlemleri}

Üç aerojel keçesi birbiriyle kıyaslandığında, her keçede ortak olarak karbon, oksijen, alüminyum, silisyum ve kalsiyum elementleri bulunurken; $\mathrm{C}$ aerojel keçesinde diğerlerinden farklı olarak bir miktar magnezyum tespit edilmiştir. Bunun muhtemel sebebinin, aerojel sentezinde kullanılan kimyasallar olduğu değerlendirilmiştir. Ayrıca A keçesinde karbon miktarının yüksekliği içerikte $\mathrm{SiC}$ bulunduğunu işaret etmektedir. Bunun da aerojel sentezleme yaklaşımlarından kaynaklandığı değerlendirilmiştir.

\subsection{Isı iletim katsayısı analizleri}

B numunesi hem keçe hem keçe+kılıf olarak en düşük 1sı iletim katsayısına sahiptir. A numunesi keçe olarak 1sı iletim katsayısında 2. sırada yer alırken keçe+kılıf olarak 3. sıradadır. C ise keçe ölçümlerinde A'dan sonra 3. sırada yer alırken, keçe+kılıf'da 2. sıradadır. C keçesinin (k1lıfsı) 1sı iletim katsayısı en yüksek olmasına rağmen saha ölçümlerinde en düşük yüzey sıcaklığını vermektedir. Kılıf eklendiğinde 1sı iletim katsayıları, kılıf malzemesinin daha yüksek 1s1 iletim katsayısına sahip olması nedeniyle yükselmektedir. C numunesine keçe+kılıf olarak bakıldığında B keçesine yakın bir 1sı iletim katsayısına sahip olduğu görülmektedir. Fakat bu durum yine de C keçesinin daha düşük yüzey sıcaklığına sahip olmasını açıklamamaktadır.

\subsection{X-ışını difraktometresi (XRD) gözlemleri}

$\mathrm{Bu}$ analizler doğrultusunda, aerojel keçe numunelerinin hepsinin amorf yapıda olduğu gözlemlenmiştir ve bu gözlem, firma kataloglarındaki fiberlerin cam elyafı olduğunu kanıtlar niteliktedir. Şekil 8, sırayla A, B ve C olacak şekilde aerojel keçelerin XRD grafiklerini göstermektedir. 


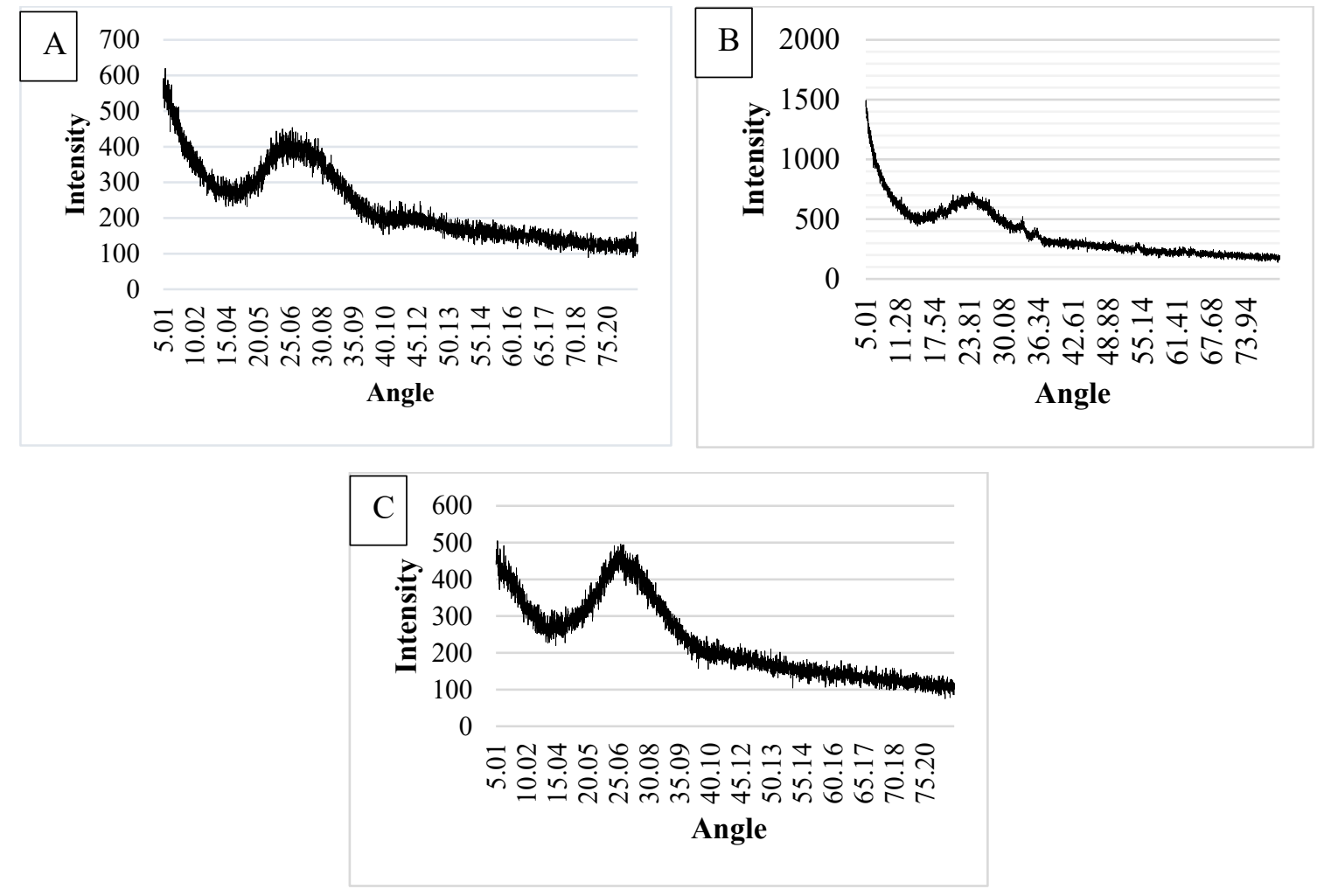

Şekil 8. Aerojel keçelerin XRD grafikleri.

\subsection{Fourier dönüşümlü kızılötesi spektrometresi (FTIR) gözlemleri}

Analiz sonucunda, her numunenin yaklaşık $1090 \mathrm{~cm}^{-1}$ dalga sayısında pik yaptığı gözlemlenmiştir. Bu pik, aerojel keçelerin Si-O-Si bağına sahip olduğunu göstermektedir. Yine her numunenin yaklaşık $810 \mathrm{~cm}^{-1}$ dalga sayısında bir başka pik yaptığı gözlemlenmiştir. Bu pik, aerojel keçelerin Si-C bağına sahip olduğunu göstermektedir. Grafiklerde $1360 \mathrm{~cm}^{-1}$ dalga sayısından başlayarak ilerleyen sabit geçirgenlik yüzdesi aerojel keçe numunelerinin sslatılamama özelliği gösterdiğini kanıtlamaktadır [13]. FTIR gözlemlerine ait grafikler Şekil 9'da verilmiştir.
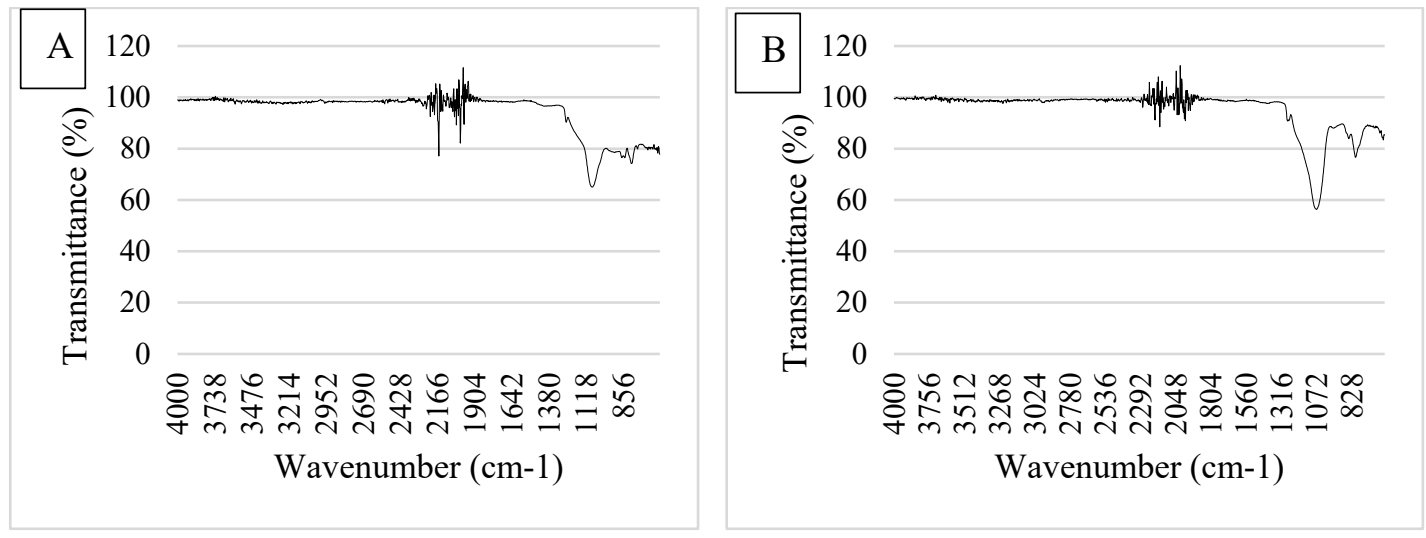


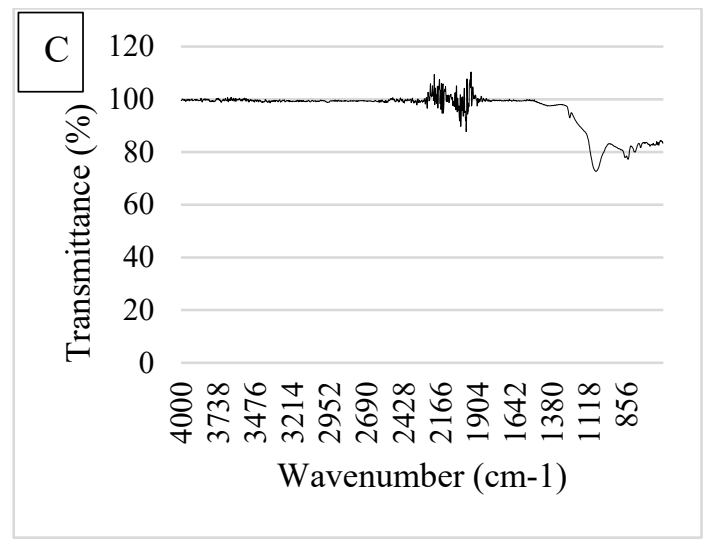

Şekil 9. Aerojel keçelerin FTIR grafikleri.

\subsection{Isı kapasitesi (özgül ısı) ölçümleri}

Ölçülen 1sı kapasitesi değerleri literatür ile uyumludur. $110^{\circ} \mathrm{C}$ 'de en yüksek 1sı kapasitesi değeri C keçesine aittir $(1,5 \mathrm{~J} / \mathrm{gK})$. C keçesini B $(1,36 \mathrm{~J} / \mathrm{gK})$ ve A keçeleri $(1,16 \mathrm{~J} / \mathrm{gK})$ izlemektedir. C keçesinin yüzey sıcaklığının daha düşük olmasının bir diğer nedeni de 1sı kapasitesinin diğer keçelere göre daha yüksek olmasıdır. Isı kapasitesinin büyük olması 1sı geçişini yavaşlatır ve yalıtım amaçlı kullanımlarda tercih nedenidir.

\section{SONUÇ (CONCLUSION)}

Bu çalışma sonunda elde edilen tüm ölçüm ve laboratuvar analiz sonuçları Tablo 2'de özetlenmiştir. Bu verilere ilaveten aerojel yalıtım keçelerinin BET yüzey alanı değerlerinin literatürde $200 \mathrm{~m}^{2} / \mathrm{g}$ civarında olduğu bilinmektedir [12]. Bu yüksek yüzey alanı ve yüksek gözenekliliğin 1sıl yalıtıma katkıda bulunduğu değerlendirilmiştir.

Tablo 2. Ölçüm ve analiz sonuçları.

\begin{tabular}{|c|c|c|c|c|c|c|c|}
\hline \multirow{3}{*}{$\begin{array}{l}\text { Sicaklık } \\
\text { ölçümleri }\end{array}$} & \multirow[b]{2}{*}{$\begin{array}{l}\text { Ölçüm } \\
\text { noktası }\end{array}$} & \multicolumn{2}{|l|}{$\mathbf{A}$} & \multicolumn{2}{|l|}{ B } & \multicolumn{2}{|l|}{$\mathrm{C}$} \\
\hline & & 9 & 10 & 6 & 7 & 3 & 4 \\
\hline & $\begin{array}{l}\text { Sicaklık } \\
\left({ }^{\circ} \mathrm{C}\right)\end{array}$ & 50,3 & 47,6 & 53,3 & 48,3 & 47,7 & 44,2 \\
\hline \multicolumn{2}{|c|}{ Kalınlık (mm) } & \multicolumn{2}{|l|}{10} & \multicolumn{2}{|l|}{15} & \multicolumn{2}{|l|}{10} \\
\hline \multicolumn{2}{|c|}{ Fiber çapları $(\mu \mathrm{m})$} & \multicolumn{2}{|l|}{10} & \multicolumn{2}{|l|}{14} & \multicolumn{2}{|l|}{10} \\
\hline \multicolumn{2}{|c|}{$\begin{array}{r}\text { Is1 iletim katsayıs1 (k1lıfsız) } \\
(\mathrm{W} / \mathrm{mK})\end{array}$} & \multicolumn{2}{|c|}{0,0312} & \multicolumn{2}{|c|}{0,0278} & \multicolumn{2}{|c|}{0,0330} \\
\hline \multicolumn{2}{|c|}{$\begin{array}{r}\text { Is1 iletim katsayıs1 (k1liflı) } \\
(\mathrm{W} / \mathrm{mK})\end{array}$} & \multicolumn{2}{|l|}{0,05} & \multicolumn{2}{|l|}{0,042} & \multicolumn{2}{|c|}{0,0433} \\
\hline \multicolumn{2}{|c|}{ Is1 kapasitesi $\left(\mathrm{C}_{\mathrm{p}}\right)(\mathrm{J} / \mathrm{gK})$} & \multicolumn{2}{|l|}{1.16} & \multicolumn{2}{|l|}{1.36} & \multicolumn{2}{|l|}{1.50} \\
\hline \multicolumn{2}{|c|}{ Yoğunluk $\left(110^{\circ} \mathrm{C}\right)\left(\mathrm{kg} / \mathrm{m}^{3}\right)$} & \multicolumn{2}{|l|}{162} & \multicolumn{2}{|l|}{178} & \multicolumn{2}{|l|}{191} \\
\hline \multicolumn{2}{|c|}{ Yoğunluk $\left(765^{\circ} \mathrm{C}\right)\left(\mathrm{kg} / \mathrm{m}^{3}\right)$} & \multicolumn{2}{|l|}{156} & \multicolumn{2}{|l|}{170} & \multicolumn{2}{|l|}{184} \\
\hline \multirow{2}{*}{\multicolumn{2}{|c|}{$\begin{array}{l}\text { Temas açısı }(\text { keçe })\left({ }^{\circ}\right) \\
\text { Temas açısı }\left(\text { kilıf }\left({ }^{\circ}\right)\right.\end{array}$}} & \multicolumn{2}{|l|}{146} & \multicolumn{2}{|l|}{100} & \multicolumn{2}{|l|}{125} \\
\hline & & \multicolumn{2}{|l|}{127} & 145 & & 129 & \\
\hline
\end{tabular}

Tablo 2'ye göre her üç numune benzer mikro-yap1 ve 1sı iletim katsayısı değerlerine sahiptir. Isıl iletkenlik ile 1s1 kapasitesi ters orantılıdır. Dolayısı ile aerojel keçeler yalıtım amaçlı kullanıldıklarından 1s1 kapasitelerinin büyük olması tercih sebebidir. En yüksek 1sı kapasitesi değeri $1.5 \mathrm{~J} / \mathrm{gK}$ ile yerli ürün olan C aerojel numunesine aittir. Isı yalıtımı için bir diğer önemli parametre de yoğunluktur. Yalıtım malzemesinin 
yoğunluğu azaldıkça 1sıl yalıtım özelliği iyileşir. Yoğunluğu en düşük olan numune A iken yerli ürün C numunesi en yüksek yoğunluk değerine sahiptir.

Temas açısının $90^{\circ}$ 'den yüksek olması malzemenin 1slatılamama özelliğini kanıtlamaktadır, temas açısı arttıkça 1slatılamama özelliği de artmaktadır. Keçe numunesi A, en yüksek temas açısı değerine sahipken, k1lıf numunesi A'nın temas açısı en düşüktür. Temas açısı tüm numunelerde $90^{\circ}$ 'nin üzerinde olduğu için tüm keçe ve kılıfların sslatılamama özelliğine sahip olduğu görülmektedir. Yerli ürün daha yoğun olmasına rağmen 1S1 yalıtımı, 1sı kapasitesi ve 1slatılamama (temas açısı) özellikleriyle yabancı menşeli ürünlerle rekabet edebilmektedir. Yerli ürünün ithal ürünlerin maliyetinden daha düşük olacağı düşünüldüğünde, hem firma hem de yalıtım ihiyacı duyan sanayi sektörü için önemli bir maddi tasarruf imkanı vermektedir.

$\mathrm{Bu}$ çalışma, silika aerojel keçelerin jeotermal tesislerde 1sı yalıtım malzemesi olarak kullanılabilirliği açısından olumlu sonuçlar vermiştir. İkinci aşama olarak keçelerin zamana bağlı olarak 1sıl performanslarındaki değişiminincelenmesi, uzun vadeli performanslarının belirlenmesi açısından gereklidir.

\section{TEŞEKKÜR (ACKNOWLEDGMENTS)}

İzmir Yüksek Teknoloji Enstitüsü-Tümleşik Araştırma Merkezi uzman ekibine ve İzmir Jeotermal Enerji San. ve Tic. A.Ş.'ne çalışma boyu süren desteklerinden dolayı teşekkür ederiz.

\section{KAYNAKLAR (REFERENCES)}

[1] J. L. Gurav, I.K. Jung, H.H. Park, E. S. Kang, D. Y. Nadargi, Silica Aerogel: Synthesis and Applications, Journal of Nanomaterials, 2010.

[2] B. E. Coffman, J.E. Fesmire, S. White, G. Gould, S. Augustynowicz, Aerogel Blanket Insulation Materials For Cryogenic Applications, AIP Conference Proceedings, (2010) 1218, 913.

[3] H. Zhang, Heat-insulating Materials and Sound-absorbing Materials, Materials in Civil Engineering, 304-423, 2011.

[4] İ. Ayçam, M. Tuna, G. Süt, Sürdürülebilirlik Ve Mimari Değişimin Yalıtım Malzemelerine Etkileri, 2010.

[5] H. C. Bayrakçı, M. Davraz, E. Başpınar, Yeni Nesil Isı Yalıtım Malzemesi: Vakum Yalıtım Paneli, SDU Journal of Technical Sciences, 1-12, 2011.

[6] S. Ng, B. P. Jelle, Y. Zhen, Ó. H. Wallevik, Effect of storage and curing conditions at elevated temperatures on aerogel-incorporated mortar samples based on UHPC recipe, Construction and Building Materials, (2016) 106, 640-649.

[7] L.W. Hrubesh, Aerogel applications, Journal of Non-Cryst. Solids 225 (1998) 335-342.

[8] J. Fricke, Aerogels and their applications, Journal of Non-Crystalline Solids 147\&148 (1992) 356-362.

[9] M. A. Hasan, R. Sangashetty, A. C. M. Esther, S. B. Patil, B. N. Sherikar, A. Dey, Prospect of Thermal Insulation by Silica Aerogel: A Brief Review, (2017) 98(2):297-304.

[10] A. S. Dorcheh, M.H. Abbasi, Silica aerogel; synthesis, properties and characterization, Journal of Materials Processing Technology, 199 (2008) 10-26.

[11] H. Thorne-Banda \& T.Miller, Aerogel by Cabot Corporation: Versatile Properties for Many Applications, Aerogels Handbook, 847-856, 2011. 
[12] K. Nocentinia, P. Achard, P. Biwole, Hygro-thermal properties of silica aerogel blankets dried using microwave heating for building thermal insulation, Energy and Buildings, 158 (2018) 14-22.

[13] U. Berardi, S. (Mark) Zaidi, Characterization of commercial aerogel-enhanced blankets obtained with supercritical drying and of a new ambient pressure drying blanket, Energy \& Buildings, 198 (2019) $542-552$. 